\title{
A Framework for Designing Cognitive Coaching Personal Learning Network (CCPLN)
}

\author{
S. Jongsermtrakoon and J. Na-Songkla
}

\begin{abstract}
Personal learning network could be handle as self-development learning supports by integrated with cognitive coaching, which believed that intrinsic motivation has positive effects on people mindset. This paper demonstrates a framework for designing the Cognitive Coaching Personal Learning Network or CCPLN. First, by literature reviews, information was collected and analysed. Key issues relevant to CCPLN were taken by expert interviews. Drawing on the findings, five basic components integrated with cognitive coaching are Connecting paths, Connecting tools, Knowledge building, Learning resources, and Coaching activities. The framework was prototyped with a three-dimension platform: Learning community, Personal creating studio, and Coaching clinic. Community provides an open space for users to exchange opinions about the teaching ideas. Clinic provides asynchronous tools for discussing on teaching ideas following cognitive coaching process. Creating studio as private space provides dynamically asynchronous tools for collecting various resources and creating the teaching ideas.
\end{abstract}

Index Terms-Personal learning network, PLN, cognitive coaching, profession development.

\section{INTRODUCTION}

On the threshold of the twenty-first century, the communication and information revolution currently underway changes the dynamics of education. Young people acquires the knowledge, skills, attitudes and values to live in the knowledge-based society of the world. They are not only required to access the different and greater educational resources but also to make the meaningful learning [1]. Teachers are likely to serve their students from diverse ways to explore, discover, learn and apply the knowledge on authentic problems, more than influences them with the contents from the textbooks [2]-[4].

Teachers must be well prepared for effective teaching and learning in a world which is changing in all spheres [1]. Teachers are able to participate in multiple professional development activities e.g. courses or workshops, education conferences or seminars, qualification programme, observation visits to other schools, individual or collaborative research, participation in a teacher network, or mentoring or peer observation and coaching [5]. However, the change in practice for teachers should be sustained and ongoing [6]. On the grounds of this, teacher-to-teacher learning activities make teachers strengthen as active

Manuscript received August 22, 2019; revised March 29, 2020. This work was supported in part by the $100^{\text {th }}$ Anniversary Chulalongkorn University Fund for Doctoral Scholarship.

The authors are with the Department of Educational Technology and Communication, Faculty of Education, Chulalongkorn University, Bangkok, Thailand (e-mail: sukandajong@gmail.com, jaitip.n@chula.ac.th). contributors to their own professional learning, rather than as passive recipients of training programs [7]. The networks can be a perfect model for working on changes in professional practices. Due to the fact, the networks differ from courses that are not one-off sessions but run through a longer period of time to provide common supports for the participants. They can come up with a secure and collaborative environment where participants can feel comfortable and certain enough to share their concerns [8].

Typical teacher network is a model of primary network where teachers are generally recipients of information from variety pathways. While a model of networked teacher purposively arrange interactions between teachers and multiple resources to promote lifelong learning in flexible learning environment as part of Personal learning network or PLN [9]. PLN consists of people and resources that support ongoing learning from observing and taking conversation with their network of colleagues and experts. It works in the belief that learning doesn't take place just in courses or training programs, but appear in the daily life activities of every teachers [10], [11].

PLN is not only a group of connections which put teachers forward to grow professionally from interacting with participants and resources in same area but also has an important key to success. That specific component is coaching [12].

From many different types of coaching which meet the different needs, cognitive coaching is quite appropriate for PLN. Because of cognitive coaching is not intend to change people behaviour following advices, but focuses extremely on growing internal thinking processes with self-directed control. The main key is a trusted relationship between a teacher and a coach based on authenticity, honesty, respect and non-judgemental counseling [13].

Afterward, teachers may improve their confidence and expertise in their instructional practices through knowledge and experience sharing with other participants in personal learning network with use cognitive coaching process to enhance their mindset to be growth.

This paper contributes to present a framework for designing Cognitive Coaching Personal Learning Network or CCPLN framework.

\section{LITERATURE REVIEWS}

\section{A. The Definition of PLN}

Teachers have been connecting with their families, friends, colleagues, acquaintances, and information from textbooks, televisions, websites, etc. to supplement their knowledge and 
professional learning for decades. That means the idea of personal learning network or PLN is a not new thing [14].

Fundamental idea of PLN similar to the learning space in teacher staffroom. Young teachers and experienced teachers sit around in the same place for influencing professional development. When the space combines with the speed of the internet, it cultivated and extended to be a group of widely connected people from anywhere at any time [15]-[17].

Personal learning network was defined by Tobin D.R. [11] as a network of participants and resources to reinforce ongoing professional development. Couros A. [9] mentioned the difference between typical teacher network and personal learning network that PLN shifts from mostly one-way learning on typical network to more engagement learning activities with people and various resources. For that reason, Couros A. [9] considered PLN as the result from individual's intention to create relationships with people, and build personal learning environment for self-development. Carter T. and Nugent J. [18] believe in the similar concept that PLN builds from a group of self-directed leaners who have individual goals and needs that join the network for sharing common interests, or helping each other solve problems. In the other hand, Richardson W. [19] clarified PLN more personally as a model of creating individual's learning space which access to education with learning resources and a network of professionals.

Accordingly, personal learning network or PLN can defines as a network of many trusted connections with people and resources to reinforce ongoing learning by gathering, communicating, creating, and sharing knowledge and experience. In addition, PLN describes as a part of personal learning environment which defines that the knowing contents are not as important as knowing where or who to connect or find them. For more details, Personal in PLN refers to personalization that participants can shape up everything in the network to exactly what, where and how they want to learn or who they want to engage with. Thus, learning in PLN is a result from the interaction with people and information in same area of interests.

\section{B. The Basic Components of PLN}

According to a majority of the reviewed studies, the five basic components of personal learning network include connecting paths, tools, contents, resources, and coaching which described as follows:

\section{1) Connecting paths}

Warlick D. [14] defined three main types of PLN with its own path of enhancement. First of all, Personally maintained synchronous connections, the network that connect to people includes local professional colleagues, distant professional colleagues, and family community and other people by using new tools such as chat, instant and text messaging, teleconference, or virtual world for meeting. Next, Personally and society maintained semi-synchronous connections which referred to collaborative idea that does not happen in real time, but nearly is. These two types of PLN show the connections between people and other participants, but the other type connects to valuable content sources. At the same time, participants in PLN turn into amplifiers by re-enter knowledge and ideas which they engaged and learnt from the network. While Couros A. [9] considered PLN as output from personal learning environment building which people connects to multiple content sources as consumer but connect to social network as both consumer and contributor. As a conclusion, first PLN basic component is Path which connect to resource as one-way consumer, but learn and re-issue knowledge and ideas back to network in two-way connections as contributor.

\section{2) Connecting tools}

Studies investigating the tools of personal learning network focused on online technology that are categorised in three groups as shown in Table I. They linked to Attwell et. Al. [20] words which mentioned that PLN technology includes from basic to advance tools, such as searching, accessing, creating contents, or commutating tools.

TABLE I: PLN TOOLS

\begin{tabular}{ll}
\hline \hline Tool types & Included in the study \\
\hline Communication tools & {$[14],[18]$} \\
Content aggregator tools & {$[9],[14],[18],[19],[21]$} \\
Content curation tools & {$[18],[19],[21],[22]$} \\
\hline \hline
\end{tabular}

1) Communication tools consist of both synchronous and semi-synchronous tool such as social network, chat or real-time text messaging, or discussion boards.

2) Content aggregator tools include search engine and aggregator tools such as social media search engines, social bookmarking, or blog aggregators.

3) Content curation tools belong to content publishing and media stocks such as blogs, micro-blogs, wikis, or image and video stocks.

\section{3) Knowledge building}

Richardson W. [19] mentioned that many paths of PLN lead people to interact with other people and content sources. As a consequence, people create knowledge which outlined the principle of connectivism which Siemens [23] identified it as a learning theory for digital age, related to chaos, network, complexity, and self-organization theories.

As said by Faisai S. [24] and Elliott C. [25] that power of the act of giving back knowledge and ideas into network can provide self-development in flexible learning environment, and collaborative leaning with others. It showed in the details of knowledge building from content curation activity that Robertson N. [26] and Albion P. [22] said that content curation is a set of necessary skills for digital era. People need to study, investigate, analyze, arrange amounts of information on the internet to create meaningful matters.

\section{4) Learning resources}

Faisai S. [24] discussed about the learning resources on personal learning network that should have both valuable contents and trusted experts in related fields for helping and supporting learners. While Colibaba A. et. Al. [15] referred series of guidebooks, video tutorials, or other materials for learning.

\section{5) Coaching activities}

Water S. [12] claimed that a very important component for building a special and unique PLN is having persons who can give advice participants to build their knowledge and ideas. It meant PLN should have coach for guild and lead learner to 
achieve theirs goals. Thus, the personal learning network definitely should have coaching systems inside [15].

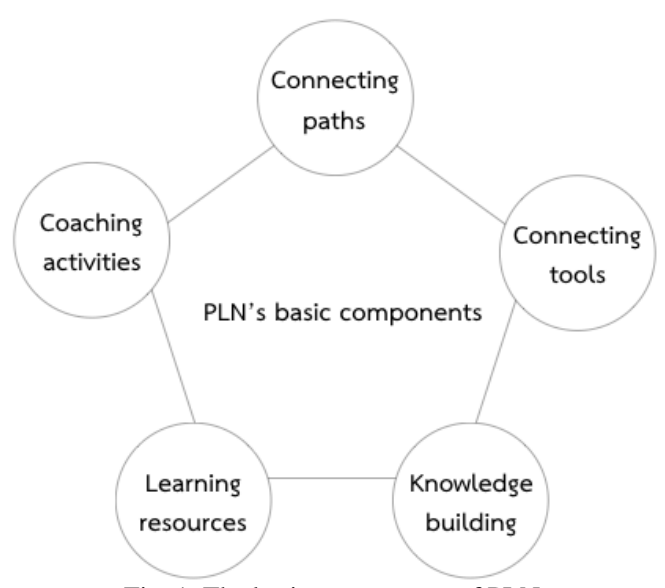

Fig. 1. The basic components of PLN.

\section{The Definition of Cognitive Coaching}

Costa A. and Garmston R. [27] described cognitive coaching as a non-judgemental and confidential relationship based on authenticity, reliability, trustiness, and empathy between coach and teacher. Costa A. and Garmston R. [13] explained more that cognitive coaching is an internal thought process which empowering by using coaching conversation to invite teachers to change thoughts without telling what to do. The important keys of cognitive coaching are non-judgement and self - directedness, thus coach need to lead teachers to observe their personal plans, actions, and self-reflections. These processes help teachers to develop cognitive skills by analyzing, operating, and evaluating. Coach need to remind their main responsibilities to support teachers to be self-sufficient [28].

\section{A Coaching Cycle}

Costa A. and Garmston R. [29], [30] presented a diagram of coaching cycle which represented a goal-oriented continuous process of learning. The three step coaching cycle includes the following steps:

\section{1) Planning}

The planning conversation is an important part of cognitive coaching that affect the significance, success, and meaning of the event. The cognitive coach illuminates and facilitates the refined details of colleague's cognitive process of planning by meditating the planner to do five dominant regions as the following: 1) clarifying goals; 2) specify success indicators; 3) anticipate approaches, strategies, decision, and how to monitor them; 4) establish personal learning focuses and processes for self-assessment; and 5) reflect on coaching process.

\section{2) Monitoring the event (observation)}

Cognitive coach assists the planner to construct the system for collecting the useful data and design the data-collecting tools for their observations. It is important to notice that data-gathering during the event is not the place for judgements, but it is an observable indicator of what student behavior will look to determine the objectivity in assessment of learning. The coach may or may not present during the event. The planner might use video in some settings to see his/her own instruction and student responses before a reflecting conversation.

\section{3) Reflecting}

After teacher participates in an event, accomplish some tasks, or sort out the challenges, the cognitive coach may contributes the cognitive processes of reflection. This is a process of self-discovery by recalling what was planned and analysing similarities and differences with what was actually occurred. There are five regions in the reflecting conversation as the following: 1) summarise impression and recall supporting information; 2) analyse causal factors by comparing, analysing, inferring, and determining relationships between cause and effect; 3) construct new learning and applications; 4) commit to application; and 5) reflect on the coaching process and explore refinements.

The cognitive coaching cycle shown in Fig. 2.

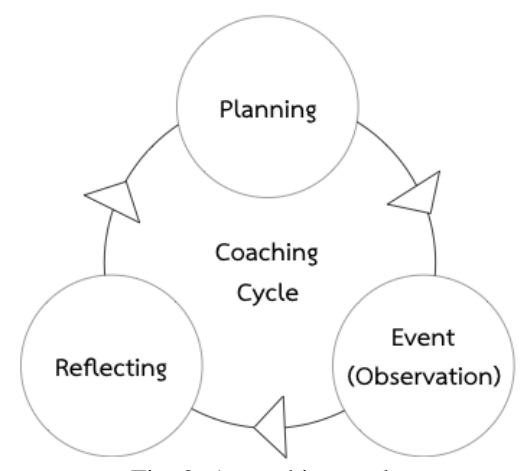

Fig. 2. A coaching cycle.

\section{METHOD}

This paper demonstrates a framework for designing the cognitive coaching personal learning network (CCPLN). The research questions for this study are as follows:

1) What are the basic components of CCPLN ?

2) What are the learning process of CCPLN?

3) What is a framework for designing CCPLN platform?

Based on the above, a literature review was carried on by organizing around and related directly to the research questions. The necessary information was collected and analyzed to create CCPLN framework. Then the framework was presented to five experts to ask for their opinions by using a five point Likert Scale which is on continuum from strongly agree ( 5 points) to strongly disagree ( 4 points). The criteria for selecting an expert panel to validate survey questions should be as follows: 1) have a doctoral degree from educational technology and communication or related field with at least 3 year working experiences 2) have experience of design and develop online professional development community / platform 3) have experience of coaching and should share an equal interest in cognitive coaching.

\section{RESUlT}

The findings reveal the opinions of five educational technology experts in two parts. First, part I was the basic components of CCPLN. Second, part II was the learning process of CCPLN. The survey results show in Table II and 
III as follows.

TABLE II: THE EXPERT OPINIONS OF THE BASIC COMPONENTS OF CCPLN

\begin{tabular}{lcc}
\hline \multicolumn{1}{c}{ Items } & $\overline{\mathrm{X}}$ & S.D \\
\hline Connecting paths & 4.67 & 0.58 \\
Connecting tools & 4.67 & 0.58 \\
Knowledge building & 4.67 & 0.58 \\
Learning resources & 4.33 & 0.58 \\
Coaching activities & 4.67 & 0.58 \\
Overall CCPLN components & 4.33 & 0.58 \\
\hline \hline
\end{tabular}

The experts totally agree with all the five basic components of CCPLN: connecting paths, connecting tools, knowledge building, learning resources, and coaching activities. The connecting paths made up of three main types. First of all, the real-time connecting path should be provided for an online meeting. Secondly, the semi-synchronous network connection between CCPLN members should be prepared for knowledge and idea-sharing. Moreover, the network should have a path that is connected to valuable learning resources. All things considered, the connecting paths in CCPLN consists of a path to reach learning resources as a consumer, and a path to learn and curate contents in two - way communication as a contributor.

According to the experts' opinions, they agreed with the three types of connecting tools in framework, including communication tools, content aggregator tools, and content curation tools. However, they gave some advice to collect more data about the use of technology in each type of tool that meets the needs of Thai teachers.

The experts asked to expand more information about how participants in the network can build their knowledge or connect to the new content. The knowledge building component talks about how participants study from various learning resources or get learning to the right people in the network. Then, they will gather appropriate information around their interesting topic and bring together all of the relevant resources to curate specific content. Therefore, experts suggested that the network should provide a personal space for collecting individual learning resources and creating content that can share what they have learned to all participants.

Learning resources are mainly showed great content which can be useful with the teachers in the network after reviewing by specialists. However, it should give opportunities for participants to suggest other interesting learning resources to their friends.

Coaching activities are provided to support learning in the process of knowledge building. This network has an achievement to raise participants' mindset to be growth. For that reason, it should use the coaching process that gives participants a chance to lead themselves to work on their jobs or practice using the knowledge they just learned. Thus, experts suggested defining clearly the coaching process.

Table III shows the result of the expert opinions of the learning process of CCPLN which uses the process of cognitive coaching.

The experts agreed with the learning process presented in the CCPLN framework, including three main processes of cognitive coaching and cognitive coach qualifications. The first step is planning. In this process, participants and their coach will make a planning conversation, which helps to find personal goals and create plans. While the participants in this network are teachers, then the conversation should support them in making lesson plans for their specific purposes. The next step is monitoring the events which let the participants implement their jobs following their ideas and record or collect pieces of evidence back to discuss with the coach in the reflecting step. In the last level of cognitive coaching, the coach will lead reflection conversations to explore and refine participants' thoughts about their implementation, results, and what they have learned. Experts suggested to declare more about the questions or conversation which cognitive coach should use to lead the planner.

TABLE III: THE EXPERT OPINIONS OF THE LEARNING PROCESS OF CCPLN

\begin{tabular}{lcc}
\hline \hline \multicolumn{1}{c}{ Items } & $\overline{\mathrm{x}}$ & S.D \\
\hline Planning & 4.67 & 0.58 \\
Monitoring the events (observation) & 4.67 & 0.58 \\
Reflecting & 4.33 & 0.58 \\
Cognitive coach qualifications & 4.67 & 0.58 \\
Overall CCPLN learning process & 4.67 & 0.58 \\
\hline \hline
\end{tabular}

The qualifications of the cognitive coach are specialists in any field, know how to lead a conversation with questions to help participants refine their thoughts, and be a supporter to inspire people.

After the discussion, a framework for designing CCPLN was revised and explained all features in next part.

\section{DISCUSSION}

\section{A. The Framework for Designing CCPLN}

A typical PLN shows idea of teacher professional development as personalized learning by connecting with people or contents in the network. Whereas, new framework of PLN expands coaching activities, one of five basic components of PLN, by emphasis as Cognitive Coaching. The following five basic components of CCPLN can be summarized as:

1) Connecting paths

2) Connecting tools

3) Knowledge building

4) Learning resources

5) Coaching activities

One focus of the CCPLN is the coaching activities which define as Cognitive Coaching, which has three step cycle as follows:

1) Planning

2) Monitoring the event (Observation)

3) Reflecting

Following the review, a framework for designing Cognitive Coaching Personal Learning Network (Fig. 3) was prototyped with a three-dimension platform: Learning community, Personal creating studio, and Coaching clinic, which describes as follow:

1) Learning community is a space that people can learn by interact with the sharing ideas and contents in anyway. This dimension needs learning resources and communication tools such as social network, chat or 
real-time text messaging, or discussion boards.

2) Personal creating studio is a private space that participant can take control and manage himself/herself own learning. The participant needs content aggregator tools, such as social media search engines, social bookmarking, or blog aggregators; to build the individual library. Subsequently, teacher in network needs content curation tools to create a project and share to learning community; such as blogs, micro-blogs, wikis, or image and video stocks.

3) Coaching clinic is a very important key of CCPLN. The coaching clinic provides a self-reflected learning following three cognitive coaching steps by using communication tools. The first step starts with planning conversation by meditating the planner to do five dominant regions as the following: 1) clarifying goals; 2) specify success indicators; 3) anticipate approaches, strategies, decision, and how to monitor them; 4) establish personal learning focuses and processes for self-assessment; and 5) reflect on coaching process. Then, with or without the coach in the events, teacher collects some evidences and presents in the observation step. In the end, coach uses reflecting conversation to facilitate the self-discovery learning from a real experience. There are five regions in the reflecting conversation as the following: 1) summarize impression and recall supporting information; 2) analyze causal factors by comparing, analyzing, inferring, and determining relationships between cause and effect; 3) construct new learning and applications; 4) commit to application; and 5) reflect on the coaching process and explore refinements.

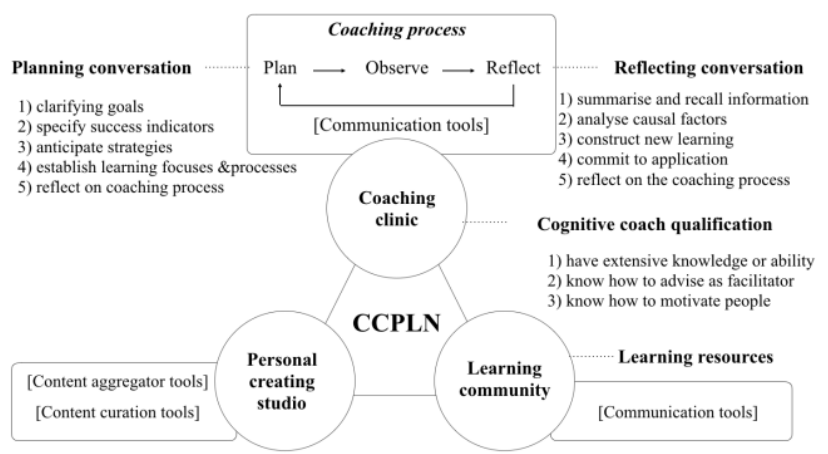

Fig. 3. CCPLN framework.

According to the above, the ideal CCPLN needs some specific qualifications as a cognitive coach. In the beginning, CCPLN may invite some specialists who match the criteria to be a coach. After a while, it should expand some sessions to create an expert coach from ordinary participants.

\section{Conclusion}

A typical Personal Leaning Network may support teacher's learning by interacting with contents or making conversation in same area of interest with colleagues, but sustainable professional development requires the action. The Cognitive Coaching Personal Learning Network adds on the cognitive coaching as a learning process. With this type of coaching, the coach facilitates them to learn from real working experience with nonjudgmental supporting conversation which including planning conversation and reflecting conversation.

Next steps, research will design the structure and system platform following a framework for designing Cognitive Coaching Personal Learning Network.

\section{CONFLICT OF INTEREST}

"The authors declare no conflict of interest".

\section{AUTHOR CONTRIBUTIONS}

Sukanda Jongsermtrakoon and Jaitip Na-Songkhla conducted the research, Sukanda analyzed the data and write the paper. All authors had approved the final version.

\section{ACKNOWLEDGMENT}

This research was supported by research reviewer, Associate Professor Dr. Petronio Bendito.

\section{REFERENCES}

[1] UNESCO. (1998). World education report 1998: Teachers and teaching in a changing world. [Online]. Available: https://unesdoc.unesco.org/ark:/48223/pf0000110875

[2] M. Hamiti and B. Reka, "Teaching with technology," Procedia-Social and Behavioral Sciences, vol. 46, pp. 1171-1176, 2012.

[3] S. Lamb. (2017). Future drontiers analytical report: Key Skills for the 21 st Century an evidenced-based review. [Online]. Available: https://education.nsw.gov.au/our-priorities/innovate-for-the-future/ed ucation-for-a-changing-world/research-findings/future-frontiers-analy tical-report-key-skills-for-the-21st-century/Key-Skills-for-the-21st-Ce ntury-Analytical-Report.pdf

[4] R. Murati and A. Ceka, "The use of technology in educational teaching," Journal of Education and Practice, vol. 8, no. 6, pp. 197-199, 2017.

[5] OECD, "The professional development of teachers," Creating Effective Teaching and Learning Environments: First Results from TALIS, 2009.

[6] S. H. Harwell, "Teacher professional development: it's not an event, it's a process," Texas: CORD, 2003.

[7] L. Calvert, Moving from Compliance to Agency: What Teachers Need to Make Professional Learning Work, Oxford: OH: Learning forward and NCTAF, 2016.

[8] TESS India. Networks: effective professional development for education change. [Online]. Available: https://www.open.edu/openlearncreate/pluginfile.php/159528/mod_re source/content/4/TEGN_Networks.pdf

[9] A. Couros, "Developing personal learning networks for open and social learning," Emerging Technologies in Distance Education, Edmonton: Au Press, Athabasca University, 2010.

[10] J. Killion, "Lessons from research: The quality of professional learning will influence results," Journal of Staff Development, vol. 34, no. 2, pp. 60-62, 2014.

[11] D. R. Tobin. (1998). Corporate learning strategies: Building your own personal learning network. [Online]. Available: http://www.tobincls.com/learningnetwork.htm

[12] S. Water. (2009). PLN Yourself! [Online]. Available: http://suewaters.wikispaces.com

[13] A. Costa and R. Garmston, Cognitive Coaching: Foundation for Ranaissance Schools, The United States of America: Christopher Gordon Publishers, 2002.

[14] D. Warlick, "Grow your personal network: New technologies can keep you connected and help you manage information overload," Learning and Leading with Technology, pp. 12-16, 2009.

[15] A. Colibaba et al., "Helping educators building personal learning networks," presented at International Conference "ICT for Language Learning", 2012.

[16] Lisahunter et al., "Professional learning places and spaces: The staffroom as site of begining teacher induction and transition," Asia-Pacific Journal of Teacher Education, vol. 39, no. 1, pp. 33-46, 2011. 
[17] T. Trust, "Professional learning networks designed for teacher learning," Journal of Digital Learning in Teacher Education, vol. 28, no. 4, pp. 133-138, 2012.

[18] T. Carter and J. Nugent, "Personal learning networks: Implications for self-directed learning in the digital age," Encyclopedia of Information Communication Technologies and Adult Education Integration, vol. 1, pp. 226-240, USA: Imprint of IGI Global, 2011.

[19] W. Richardson, "Building your own personal learning network," Massachusetts Computer Using Educators, pp. 1-3, 2008.

[20] Attwell et al., "Appropriating technologies for contexual knowledge: Mobile personal learning environments," Communications in Conputer and Information Science, vol. 49, pp. 15-25, 2009.

[21] A. Mossman, "Personal learnig networks: Exploring the information needs of educators," The Degree of Education Specialist in Learning Resources, University of Central Missouri, 2012.

[22] P. Albion. (2014). From creation to curation: evolution of an authentic assessment fir learning task. [Online]. Available: https://eprints.usq.edu.au/26034/20/Albion_SITE_2014_AV.pdf

[23] G. Siemens. (2004). Connectivism: A Learning Theory for the Digital Age. [Online].

Available: http://www.elearnspace.org/Articles/connectivism.htm

[24] S. Faisal, "Personal learning network: A powerful tool for professional development," Paradigm Shift in Libraries: A Festchrift to Rev. Fr. Jose Viruppel, 2015.

[25] C. Elliott, "We are not alone: The power of personal learning networks," Synergy, vol. 7, no. 1, pp. 47-50, 2009.

[26] N. Robertson. (2012). Content Curation and the School Librarian in Knowledge Quest: Personal Learning Networks - Online Exclusive. [Online].

Available: http://www.ala.org/aasl/sites/ala.org.aasl/files/content/aaslpubsandjou rnals/knowledgequest/docs/KQNovDec12_OE_TAGS.pdf

[27] A. Costa and R. Garmston, Cognitive Coaching: A Foudation for Renaissance Schools, Norwood: Chirstopher-Gordon Publishers, Inc., 1994.

[28] R. Garmston, C. Linder, and J. Whitaker, "Reflections on cognitive coaching," Educational Leadership, vol. 51, no. 2, pp. 57-61, 1993.

[29] A. Costa and R. Garmston, Cognitive Coaching Foundation Seminar Leanring Guide, The United States of America Center of Cognitive Coaching, 2011.

[30] A. Costa and R. Garmston, Cognitive Coaching: Developing Self-deirected Leaders and Learners, Maryland: Rowman \& Littlefield, 2016.
Copyright $(2020$ by the authors. This is an open access article distributed under the Creative Commons Attribution License which permits unrestricted use, distribution, and reproduction in any medium, provided the original

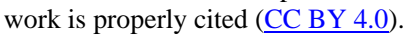

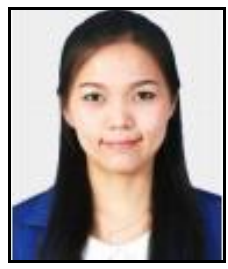

Sukanda Jongsermtrakoon was born in Surin Thailand on December 28, 1984. She is listed in doctoral program of educational technology and communication at Chulalongkorn University, Bangkok, Thailand, 2014 to present. She is currentky a lecturer at Panyapiwat Institute of Management. She was education technology consultant at Iverson Training Center who handled technology integrating program in many schools and colleges. She was a teaching and research assistant in the division of educational technology and communication at Faculty of Education, Chulalongkorn University, 2012-2014. Background of her profession was an outstanding computer teacher, awarded by the Bangkok Metropolitant Office in the year of 2012, and Bangkok Christian College was her affiliation during 2007-2012. Her inspired work is in Open Educational Resources and MOOCs; then came to her document research on "A Group Investigation Learning System for Open Educational Resources to Enhance Student Teachers' Digital Literacy and Awareness in Information Ethics" in International Journal of Information and Education Technology, 2012.

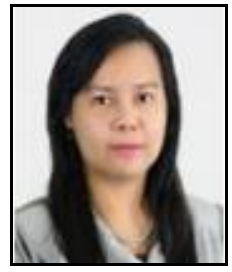

Jaitip Nasongkhla is a Ph.D. She has been with Chulalongkorn University, Bangkok, Thailand since 1998. She is currently the head of Department in Educational Technology and Communication at Faculty of Education. Her publications are in the area of e-learning, tablet technology for teachers professional development and pre-service teacher Education. Her contributions have also covered the area of Educational Policies and mainly on the open content for Life Long learning Currenlty as OER in liflong learning, tablet technology for a classroom innovative action research (CIAR), collective learning through crit. Her international research networks in Asia and Europe have currently been committed to the area of massive open online courseware. 